\title{
Dynamic and Quasi-Static Testing and Modeling of Hot Stamped Tailor-Welded Axial Crush Rails ${ }^{+}$
}

\author{
Cale Peister ${ }^{1, *}$, Cameron O'Keeffe ${ }^{1}$, Jose Imbert ${ }^{1}$, Clifford Butcher ${ }^{1}$, Michael Worswick ${ }^{1}$, \\ Skye Malcolm ${ }^{2}$, Jim Dykeman ${ }^{2}$, Cyrus Yau ${ }^{3}$, Ron Soldaat ${ }^{4}$ and Willie Bernert ${ }^{4}$ \\ 1 Department of Mechanical and Mechatronics Engineering, University of Waterloo, Waterloo, ON N2L 3G1, \\ Canada; cokeeffe@uwaterloo.ca (C.O.); jmsimbertboyd@uwaterloo.ca (J.I.); \\ cbutcher@uwaterloo.ca (C.B.); michael.worswick@uwaterloo.ca (M.W.) \\ 2 Honda R \& D Americas Inc., Raymond, OH 43067, USA; smalcolm@oh.hra.com (S.M.); \\ jdykeman@oh.hra.com (J.D.) \\ 3 Promatek Research Centre, Cosma International, Brampton, ON L6T 5R3, Canada; \\ cyrus.yau@magna.com \\ 4 ArcelorMittal Dofasco, Hamilton, ON L8N 3J5, Canada; ronald.soldaat@arcelormittal.com (R.S.); \\ willie.bernert@arcelormittal.com (W.B.) \\ * Correspondence: cale.peister@uwaterloo.ca; Tel.: +1-519-832-7923 \\ + Presented at the 18th International Conference on Experimental Mechanics (ICEM18), Brussels, Belgium, \\ 1-5 July 2018.
}

Published: 26 September 2018

\begin{abstract}
In the current research, the use of tailor-welded blanks (TWBs) comprising Usibor ${ }^{\circledR} 1500-$ AS laser welded to more ductile Ductibor ${ }^{\circledR} 500-A S$ is considered. The TWBs were hot stamped to form top-hat cross-section channels with axially tailored properties. Axial crush rails were assembled by spot welding together two of these hot stamped channels along their flanges. The tailored rails were crush tested under dynamic (crash) and quasi-static conditions using an $855 \mathrm{~kg}$ crash sled facility at $10.6 \mathrm{~m} / \mathrm{s}$ impact speed, and a $670 \mathrm{kN}$ servo-hydraulic press at $0.5 \mathrm{~mm} / \mathrm{s}$, respectively. Non-tailored channels composed entirely of Ductibor ${ }^{\circledR} 500$-AS were also tested for base material characterization and as a comparison to the tailored conditions. Numerical models of the crash experiments were developed. The material models include measured fracture loci using the generalized incremental stress state dependent damage model (GISSMO), with rate sensitive constitutive behavior. Spot weld failure was also considered based on tests of spot welded coupons. The accuracy of the predicted force-displacement and energy absorption response, extent of parent metal cracking, and extent of weld failure are evaluated in comparison to the experiments. The difference in response between quasi-static and dynamic testing is also evaluated.
\end{abstract}

Keywords: hot stamping; tailor-welded blanks; axial crush; quasi-static crush; dynamic crush

\section{Introduction}

The demand to meet improved fuel economy and passenger safety standards in modern automobiles has resulted in the development of new lightweight materials and manufacturing processes. One such metal forming process is hot stamping, wherein a boron steel blank is heated above its austenization temperature in a furnace, giving it good formability and minimal springback at this elevated temperature. It is then formed into the desired shape between cooled dies, causing rapid cooling of the sheet and phase transformation from austenite to martensite [1]. This creates an ultra-high strength steel (UHSS) martensitic material with tensile strengths as high as $1500 \mathrm{MPa}$, which allows for vehicle weight reduction through reduction in sheet thickness. 
One limitation of UHSS materials is their relatively low ductility and limited energy absorption which has motivated current research that considers tailoring strategies to introduce more ductile regions within components that are capable of absorbing crash energy. One such tailoring strategy is the tailored in-die heating (IDH) process which uses a stamping die that is heated in certain areas, reducing the cooling rate and forming a more ductile bainitic/ferritic microstructure [1], while continuing to form martensite in the cooled areas of the die. Another tailoring strategy is the hot stamping of tailor-welded blanks (TWBs), which comprise multiple sheets with varying material properties and/or thicknesses [2] that are laser welded together along their edges. Múnera et al. [3] found a reduction in intrusion into the passenger compartment and a potential for significant weight savings when using hot stamped TWBs. These hot stamped TWBs combine the intrusion resistance of hot stamped materials with the energy absorption of ductile tailored regions to reduce weight while maintaining occupant safety.

Resistance spot welding is commonly used in automotive applications to fasten sheet metal parts without adding mass. Eller et al. [4] and O'Keeffe et al. [5] have studied the mechanical behaviour of spot welded hot stamped steels. The behaviour of joints in martensitic materials was observed to be controlled by the softened heat affected zone (HAZ) around the weld. The abrupt change in material properties causes strain to localize in the softened region and can cause the weld to pull out.

Axial crush refers to cases in which the direction of impact is along the length of the part. Structures optimized for axial crush are often found in the front and rear crush structure of an automobile. The current work focuses on improving the performance of axial crush rails by applying hot stamped TWBs. The TWBs comprise two hot stamping steels: Usibor ${ }^{\circledR} 1500-A S$ which hardens during quenching to reach a tensile strength of $1300 \mathrm{MPa}$ or higher, and Ductibor ${ }^{\circledR} 500-\mathrm{AS}$ which does not harden as much, and forms a ductile material with about $600 \mathrm{MPa}$ tensile strength [3]. In previous work by Peister et al. [6,7], TWB rails with $1.2 \mathrm{~mm}$ common gauge, and $1.2 \mathrm{~mm}$ to $1.6 \mathrm{~mm}$ multi-gauge were tested dynamically. The current work focuses on a thicker $1.6 \mathrm{~mm}$ common gauge, and will investigate rate effects by conducting quasi-static tests in addition to dynamic tests. Top-hat channels were formed from these TWBs such that the properties were tailored along their length and then spot welded together to form axial crush rails. Quasi-static testing was performed using a hydraulic press, and dynamic testing was performed on the University of Waterloo (UW) crash sled. A numerical model of the dynamic experiment was created to predict the crush behaviour, including prediction of spot weld failure. The goal of this work is to investigate the effect of deformation rate on the crush performance of these multi-alloy parts, and to predict the failure of resistance spot welds in a numerical crush model.

\section{Experimental Setup}

\subsection{Specimen Preparation}

Forming blanks for this work were water jet cut from sheets of $1.6 \mathrm{~mm}$ thick Ductibor ${ }^{\circledR} 500-\mathrm{AS}$ for non-tailored rails, and from laser welded sheets of $1.6 \mathrm{~mm}$ Ductibor ${ }^{\circledR} 500$-AS and $1.6 \mathrm{~mm}$ Usibor $^{\circledR}$ 1500-AS for tailored rails. They were formed in a tool with a water-cooled die cavity and punch, and the binder and flange region at room temperature. Each blank was heated for seven minutes in an electric furnace at $930^{\circ} \mathrm{C}$, transferred to the hydraulic press and quickly formed. The press was held closed with a force of $588 \mathrm{kN}$ for $10 \mathrm{~s}$ to rapidly quench the part and cause phase transformation to the desired microstructures, after which the part was removed and allowed to air cool to room temperature. Vickers hardness tests were performed to confirm the as-formed parts had the expected hardness profile. This forming process is described in more detail by Peister et al. [8].

Two of these formed channels were spot welded together along their flanges with a $25 \mathrm{~mm}$ weld pitch to form axial crush rails (Figure 1). The rails were trimmed $90 \mathrm{~mm}$ shorter through laser cutting to reduce the likelihood of global buckling, giving a final specimen length of $500 \mathrm{~mm}$. In the TWB parts, the $90 \mathrm{~mm}$ was removed from the Usibor ${ }^{\circledR} 1500$-AS section while the full length of the Ductibor ${ }^{\circledR}$ 500-AS section was preserved. Indents were formed $4 \mathrm{~mm}$ deep into the impacted end of the rail to 
reduce the initial peak load and control where initiation of the first folds occurred. Holes were laser cut into both ends of the rail to allow for mounting to bosses to fixture the part (Figure 1).

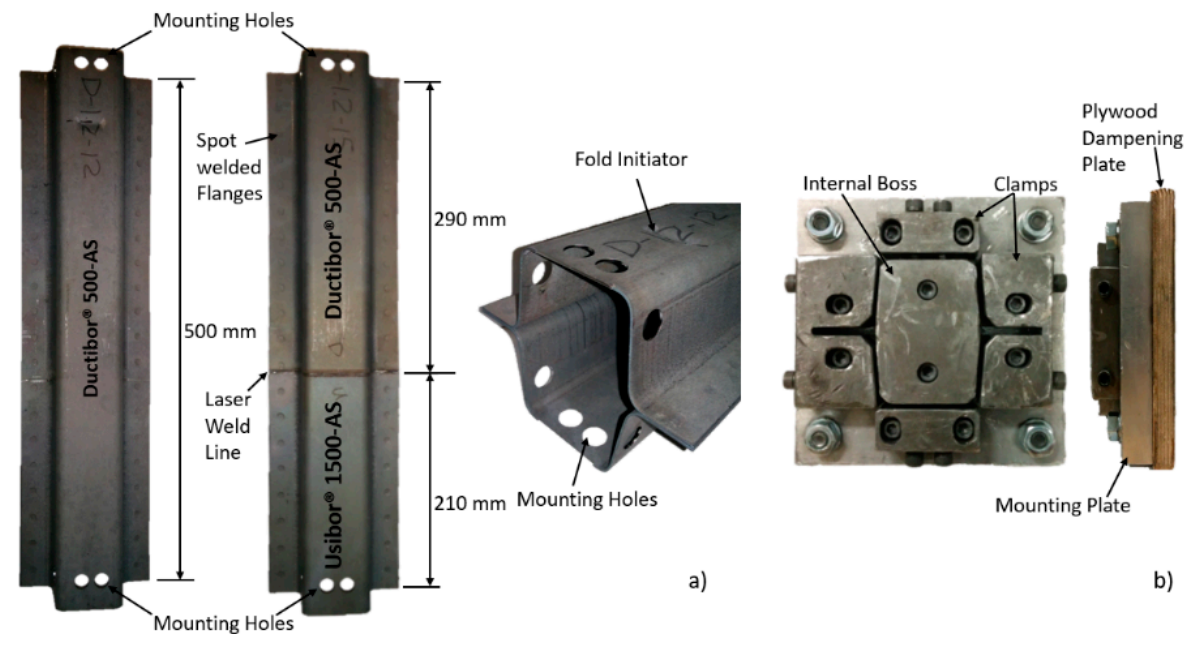

Figure 1. (a) Axial crush rail specimens; (b) Boss that is clamped to impacted end of the rail [6].

\subsection{Dynamic Axial Crush}

Dynamic axial crush experiments were performed using the Seattle Safety D780-3.7 crash sled at the University of Waterloo (UW), shown in Figure 2. For TWB parts, the Usibor ${ }^{\circledR} 1500$-AS end of the part was mounted in a boss $50 \mathrm{~mm}$ deep that was attached to the fixed impact wall. At the Ductibor $^{\circledR} 500$-AS end of the part a boss $25 \mathrm{~mm}$ deep was clamped on, with a piece of $19 \mathrm{~mm}$ thick plywood damping the impact between the sled and this boss. The non-tailored rails were mounted in the same manner. To absorb the remaining kinetic energy of the sled after the test specimen had been crushed by $160 \mathrm{~mm}$, aluminum honeycomb arrestor blocks were arranged in stacks of $160 \times 160$ $\mathrm{mm}$ and $140 \times 140 \mathrm{~mm}$ on either side of the test specimen. An additional honeycomb arrestor with a high stiffness was mounted below the test specimen to rapidly stop the sled in the event that the primary arrestors failed. The tests were performed at a speed of $10.6 \mathrm{~m} / \mathrm{s}$ with a sled mass of $855 \mathrm{~kg}$.

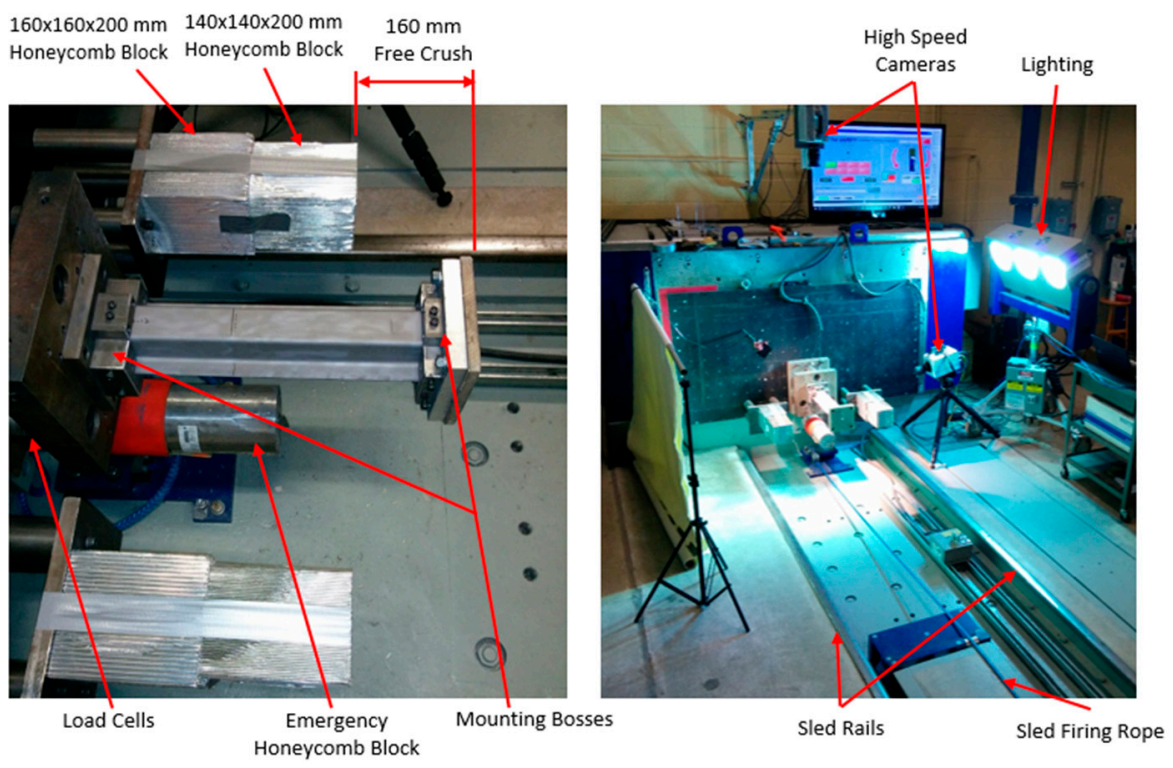

Figure 2. Dynamic axial crush test setup at UW [6].

The deceleration of the crash sled was measured using two on-board accelerometers. The results were averaged, then double integrated to determine the displacement of the sled. The force transmitted through the specimen was measured by three piezoelectric load cells mounted between 
the mounting boss and the fixed wall. From these results, the force-displacement and energy absorption were determined. The folding behaviour was captured by two high speed cameras at 5000 frames per second, mounted above and beside the specimen. It was found in early tests that the video was obscured by dust released by the aluminum-silicon coating on the hot stamped material. In subsequent tests, this coating was removed from the outside of the rails by sandblasting.

\subsection{Quasi-Static Axial Crush}

Quasi-static axial crush experiments were performed using the $670 \mathrm{kN}$ servo-hydraulic press shown in Figure 3. This press has four large guide posts that react lateral loads during crushing to protect the actuator. The Usibor ${ }^{\circledR} 1500$-AS end of the part was mounted to the same lower boss as in the dynamic test and clamped to the table, and the same upper boss was mounted to the Ductibor ${ }^{\circledR}$ 500-AS end of the part. Initially the upper boss was left unclamped like in the dynamic tests, but at the much lower displacement speed it was found to slide laterally and rotate as the specimen crushed, so it was clamped to the punch as well, with the plywood dampening plate removed. The experiments were performed at a speed of $0.5 \mathrm{~mm} / \mathrm{s}$ to a total displacement of $250 \mathrm{~mm}$. A LabVIEW program was used to record displacement measured from a potentiometer, and force was measured using a pack of three load cells mounted between the upper and lower parts of the punch. Video was recorded from two angles using Nikon D3200 cameras mounted on tripods.

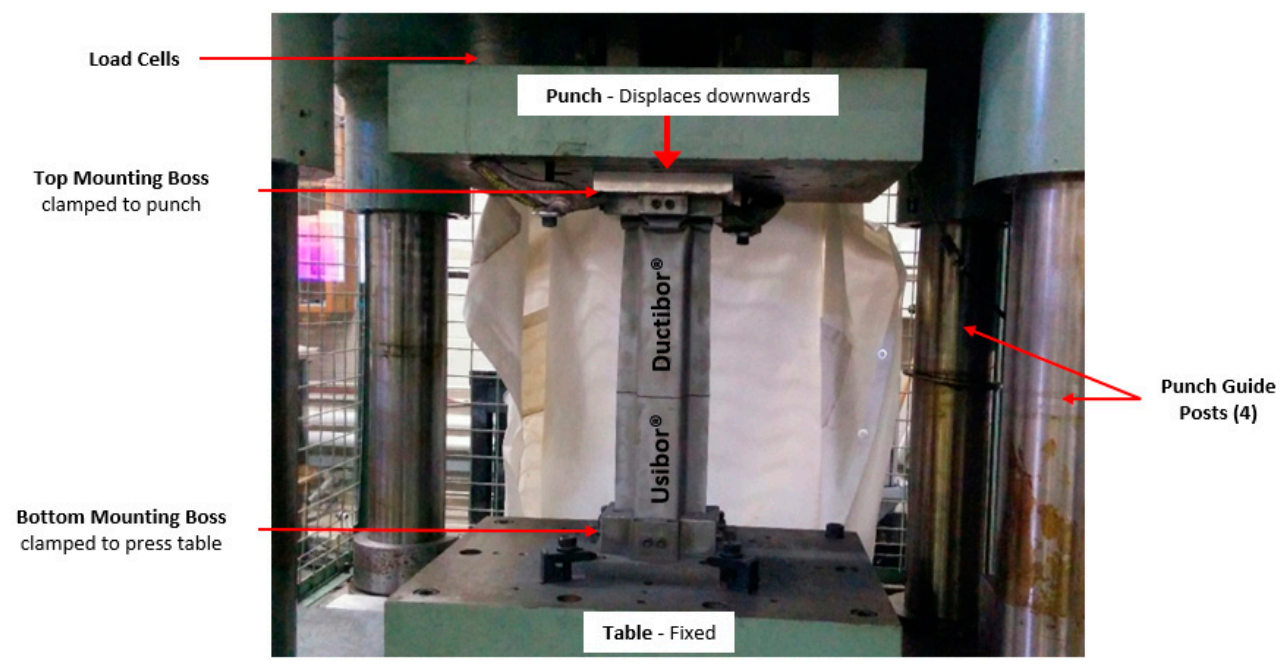

Figure 3. Quasi-static axial crush test setup in hydraulic press.

\section{Numerical Model Setup}

Numerical models of the dynamic crush experiments were created using the LS-DYNA R9.0 commercial finite element package and are further described by Peister et al. [6]. The rail sections were modelled using $2.5 \mathrm{~mm}$ four-noded Belytschko-Tsay shell elements with 7 through-thickness integration points. The impacted boss was modeled with rigid $9.5 \mathrm{~mm}$ tetrahedral solid elements, and was impacted with a rigid plate of shell elements with the mass and initial velocity of the sled. The elements in the first $50 \mathrm{~mm}$ of the fixed end were fully constrained to simulate clamping. At the laser weld line in the TWB parts, the nodes in the adjacent materials were made coincident and no weld properties were assigned. The fracture locus adopted to describe the Usibor ${ }^{\circledR} 1500$-AS was developed by ten Kortenaar [9] and updated using plane strain bend data by Cheong et al. [10]. The flow curves for Usibor ${ }^{\circledR} 1500$-AS were generated from the "Tailored Crash Model" (TCM) due to Bardelcik et al. [11]. For Ductibor ${ }^{\circledR}$ 500-AS, flow curves were created from experimental data [12] with rate sensitivity approximated by the TCM [11] and fracture neglected because it was not observed in experiments. Penalty-based contact is assigned between the specimens and bosses, and for selfcontact of the rail with itself during folding.

The spot welds were modeled using the MAT_100 material card and spot weld beam elements. Failure was not observed in the Ductibor ${ }^{\circledR} 500$-AS spot welds, so these were modelled without failure. 
Weld failure was observed in the Usibor ${ }^{\circledR} 1500$-AS section due to the heat affected zone softening in high strength materials, so weld failure was added to the model. The failure parameters were calibrated through coupon testing and modeling performed by $\mathrm{O}^{\prime} \mathrm{Keeffe}$ et al. [5]. The fade energy parameter was used to simulate the load sharing and pull out that occurs as a weld fails. It prevents rapid unzipping by sustaining load after the weld begins to fail. Fade energies between $500 \mathrm{~mJ}$ and $1000 \mathrm{~mJ}$ were studied.

\section{Results}

The loads from the dynamic and quasi-static experiments for both material conditions are compared in Figure 4. Each curve represents the average of three or more tests performed under the same conditions. Both material conditions have an initial peak load of about $420 \mathrm{kN}$ in the dynamic test, which is much higher than the $240 \mathrm{kN}$ peak measured in the quasi-static tests. The first $200 \mathrm{~mm}$ of the curve is the same for each material because in both cases the Ductibor ${ }^{\circledR} 500$-AS is crushing first. After this initial peak, the dynamic load level reduces to about $120 \mathrm{kN}$, while the quasi-static load level reduces to about $110 \mathrm{kN}$. After about $200 \mathrm{~mm}$ of displacement, the Usibor ${ }^{\circledR} 1500$-AS section of the rail begins to crush in the TWB specimens, increasing the load to about $275 \mathrm{kN}$ in both the dynamic and quasi-static tests. The lower force levels cause the energy absorption to be lower in the quasi-static tests than in the dynamic tests, with the TWB parts absorbing $27.1 \mathrm{~kJ}$ and $31.3 \mathrm{~kJ}$ respectively after $238 \mathrm{~mm}$ of crush distance. Similarly, the Ductibor ${ }^{\circledR} 500$-AS rails absorbed $24.8 \mathrm{~kJ}$ quasi-statically and $29.9 \mathrm{~kJ}$ dynamically after $250 \mathrm{~mm}$ of crush. The deformed shape of the sample specimens in Figure 5 shows that the quasi-statically crushed specimens formed tighter folds and experienced more stable folding behaviour with less buckling than the dynamic tests.
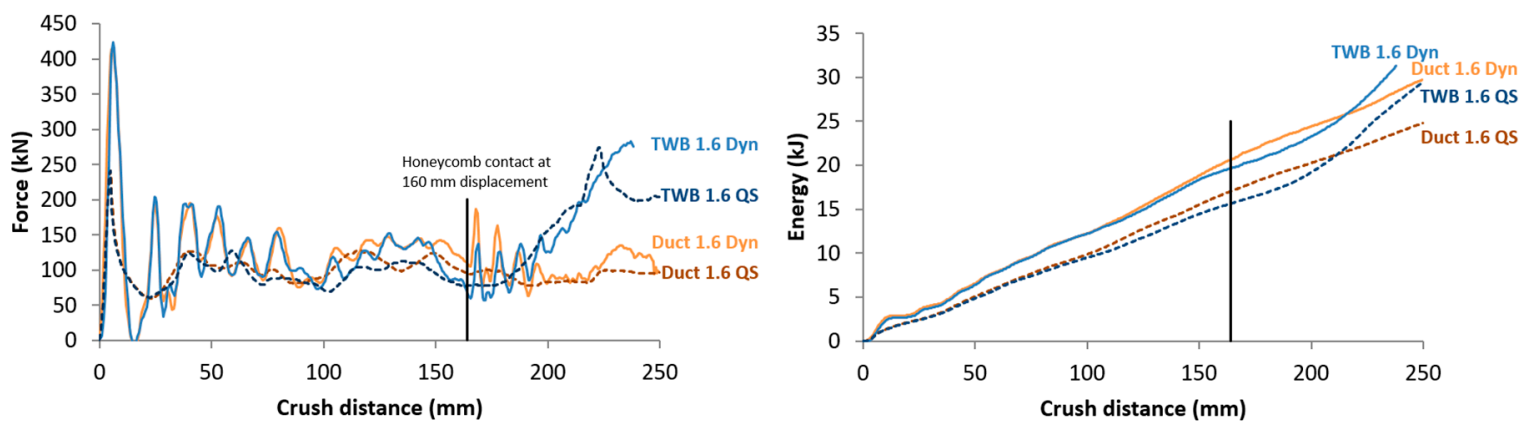

Figure 4. Comparison of crush response under dynamic (Dyn) and quasi-static (QS) conditions.
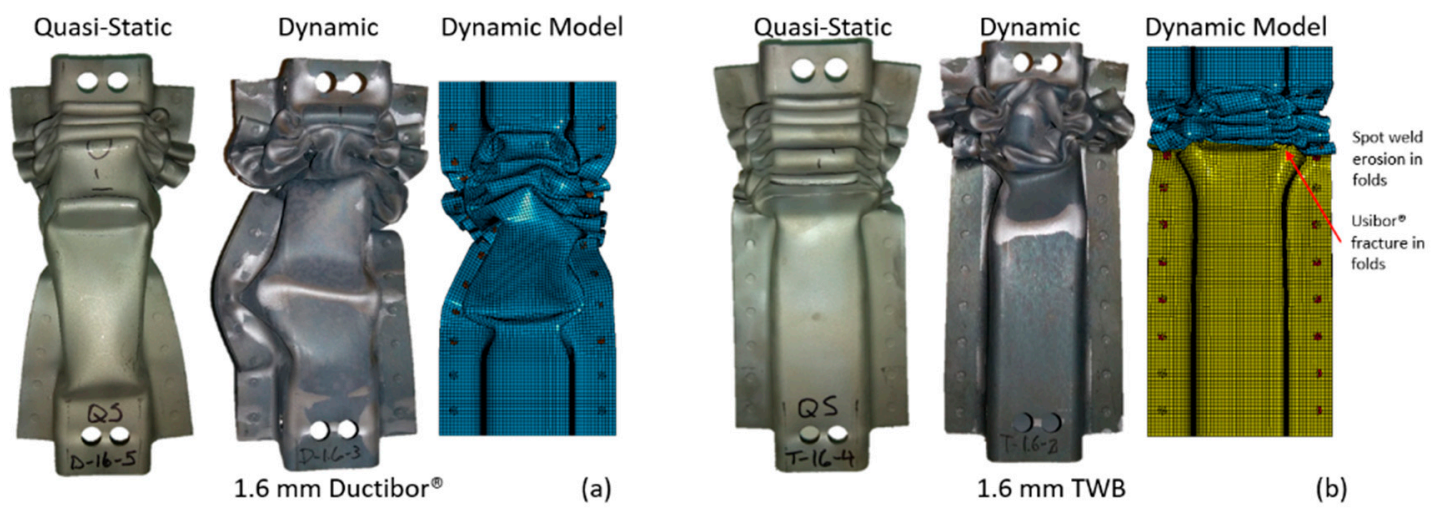

(a)

(b)

Figure 5. Crushed rails from quasi-static, dynamic experiments and model in (a) Ductibor ${ }^{\circledR} 500-A S$ and (b) TWBs.

The loads from the dynamic experiments are compared to the numerical model predictions in Figure 6. In both materials there was more oscillation in the experimental data than was predicted in the model; however, the data tends to oscillate around the predicted force level. For the fully Ductibor $^{\circledR}$ 500-AS rails, the force level was under predicted, particularly between $125 \mathrm{~mm}$ and 175 
mm displacement, resulting in the total energy absorption being under predicted by $4 \mathrm{~kJ}$. In the TWB rails, the model fit the experiments more closely, with the predicted and measured energy absorption being identical at full displacement. Figure 5 shows that the model of dynamic crush accurately predicts unstable folding in the fully Ductibor ${ }^{\circledR} 500$-AS part, and an accurate extent of Usibor ${ }^{\circledR} 1500$ AS fracture in the TWB part. The weld failure model predicted some erosion of the spot weld elements as the tight folds were formed.
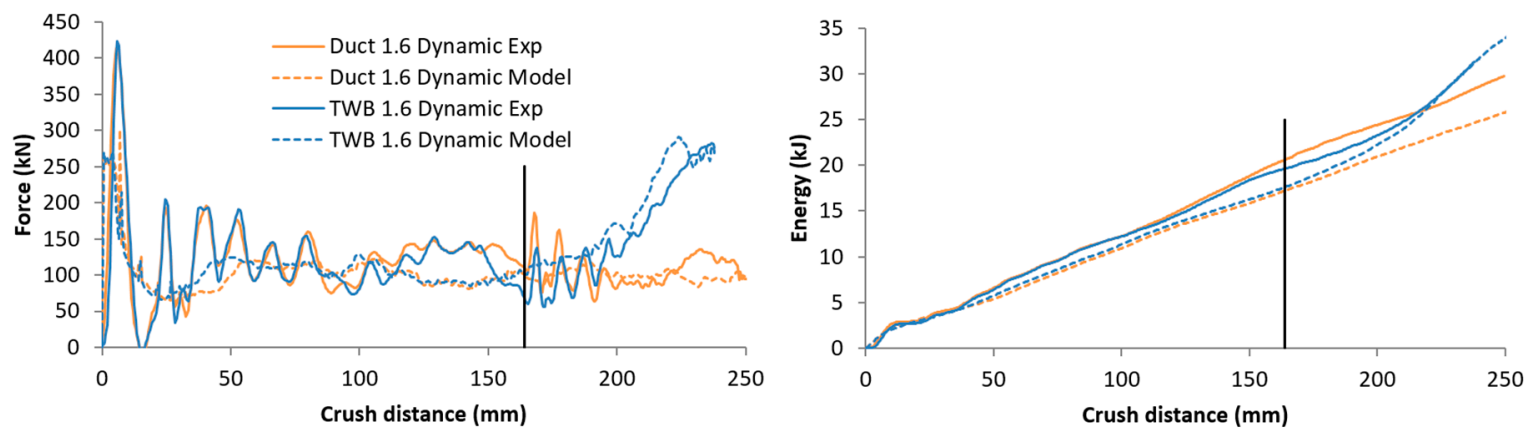

Figure 6. Comparison of dynamic experiments to numerical models.

\section{Discussion and Conclusions}

The TWB and fully Ductibor ${ }^{\circledR}$ 500-AS specimens crushed dynamically absorbed $31.3 \mathrm{~kJ}$ and 29.9 $\mathrm{kJ}$, respectively, over their full crush distances. The quasi-static specimens absorbed $27.1 \mathrm{~kJ}$ and 24.8 $\mathrm{kJ}$ over the same crush distances, a reduction of $13.4 \%$ and $17.1 \%$. The quasi-static tests produced more stable folding, in part due to the specimen being constrained at both ends. The numerical model created in LS-DYNA for dynamic crush under-predicts the load and energy absorption in the Ductibor $^{\circledR}$ 500-AS specimens. The model accurately predicted the load, energy absorption, and extent of material and spot weld failure in the TWB specimens. By setting the fade energy parameter in the spot weld model to $1000 \mathrm{~mJ}$, failure propagation was calibrated to reflect the experiments.

Author Contributions: C.P., M.W. and C.B. conceived and designed the experiments; C.P. and J.I. performed the experiments; C.P. hot stamped the specimens, analyzed the experimental data, created the numerical model, and wrote the paper; C.O. created the spot weld failure model; C.B., S.M. and J.D. contributed material data; C.Y. and E.D. contributed spot welding and laser cutting of the test specimens; and R.S. and W.B. provided the Ductibor $^{\circledR}$ 500-AS and Usibor ${ }^{\circledR} 1500-A S$ TWBs used in this work.

Acknowledgments: Support for this project from Honda R\&D Americas, the Promatek Research Center (Cosma International), ArcelorMittal, the Natural Sciences and Engineering Research Council, the Canada Research Chair Secretariat, and the Canada Foundation for Innovation is gratefully acknowledged.

Conflicts of Interest: This research was supported in part by Honda R\&D Americas, the Promatek Research Center (Cosma International) and ArcelorMittal who contributed to authorship of this paper and approved publication. Beyond this sponsor involvement, the authors declare no other potential conflict of interest.

\section{References}

1. Karbasian, H.; Tekkaya, A.E. A review on hot stamping. J. Mater. Process. Technol. 2010, 210, $2103-2118$.

2. Merklein, M.; Johannes, M.; Lechner, M.; Keppert, A. A review on tailored blanks-Production, applications and evaluation. J. Mater. Process. Technol. 2014, 214, 151-164.

3. Múnera, D.; Pic, A.; Abou-Khalil, D.; Schmit, F. Innovative Press Hardened Steel Based Laser Welded Blanks Solutions for Weight Savings and Crash Safety Improvements. SAE Int. J. Mater. Manuf. 2008, 1, 472-479.

4. Eller, T.K.; Greve, L.; Andres, M.; Medricky, M.; Geijselaers, H.J.; Meinders, V.T.; van den Boogaard, A.H. Plasticity and fracture modeling of the heat-affected zone in resistance spot welded tailor hardened boron steel. J. Mater. Process. Technol. 2016, 234, 309-322.

5. O'Keeffe, C.; Imbert-Boyd, J.; Worswick, M.; Butcher, C.; Malcolm, S.; Dykeman, J.; Penner, P.; Yau, C.; Soldaat, R.; Bernert, W. Examination of Mode I loading on resistance spot weld groups in tailored hot stampings. In Proceedings of the DYMAT's 23rd Technical Meeting, Trondheim, Norway, 12-14 September 2017. 
6. Peister, C.; George, R.; Omer, K.; Bernert, W. Tailor Welded Hot Stamped Automotive Axial Crush Structures: Crash Experiments and Modelling. In Proceedings of the 2017 International Automotive Body Congress, Dearborn, MI, USA, 20-21 September 2017.

7. Peister, C.; George, R.; Omer, K.; Worswick, M.J.; Malcolm, S.; Dykeman, J.; Yau, C.; Soldaat, R.; Bernert, W. Crash Testing and Modelling of Hot Stamped Multi-Gauge Tailor-Welded Automotive Axial Crush Structures. In Proceedings of the 2nd International Conference on Impact Loading of Structures and Materials, Xi'an, China, 7-11 May 2018.

8. Peister, C.; George, R.; Omer, K.; Worswick, M.J.; Malcolm, S.; Dykeman, J.; Yau, C.; Soldaat, R.; Bernert, W. Forming of an axially tailored automotive channel section through hot stamping of tailor-welded blanks. J. Phys. 2017, 896, 012052.

9. ten Kortenaar, L. Failure Characterization of Hot Formed Boron Steels with Tailored Mechanical Properties. Master's Thesis, University of Waterloo, Waterloo, ON, Canada, 2016.

10. Cheong, K.; Omer, K.; Butcher, C.; George, R.; Dykeman, J. Evaluation of the VDA 238-100 tight radius bending test using digital image correlation strain measurement. J. Phys. 2017, 896, 012075.

11. Bardelcik, A.; Worswick, M.J.; Wells, M. The influence of martensite, bainite and ferrite on the as-quenched constitutive response of simultaneously quenched and deformed boron steel-Experiments and model. Mater. Des. 2014, 55, 509-525.

12. Dykeman, J. (Honda R\&D Americas Inc., Torrance, CA, USA). Private communication, 2018.

(C) 2018 by the authors. Licensee MDPI, Basel, Switzerland. This article is an open access article distributed under the terms and conditions of the Creative Commons Attribution (CC BY) license (http://creativecommons.org/licenses/by/4.0/). 